\title{
STOMATITIS AND APLASTIC ANEMIA DUE TO NEO-ARSPHENAMIN *
}

JOSEPH EARLE MOORE, M.D., and ALBERT KEIDEL, M.D.

BALTIMORE

Among the late reactions occurring after the use of arsphenamin products in the treatment of syphilis, the most serious are dermatitis, stomatitis, jaundice and encephalitis. In this country the last is rarely encountered, although it is apparently quite frequent in Europe. The other reactions mentioned are more common and are thus of greater practical importance. Dermatitis and stomatitis appear to be closely allied. Previous papers ${ }^{1}$ from this clinic have discussed this interrelation, and have drawn attention to a characteristic common to both types of reaction, namely, a striking alteration in the blood picture during life and marked changes in the bone marrow at necropsy.

Since any data which may tend to throw light on the mechanism of these reactions should be presented, the following case report is believed to be worthy of record.

\section{REPORT OF A CASE}

History.-A white woman, aged 50, had been twice married. The first husband had died some years ago, cause unknown. The issue from this marriage was one daughter, well at the age of 28 , with no stigmas of congenital syphilis, who herself has several normal children. During the first marriage there were no miscarriages and no history of possible signs of syphilis.

In 1918 , the patient married again, a marriage of convenience, with a man twelve years her senior. Owing to the character of the marriage there was no sexual intercourse until February, 1919, and this took place only once. Intromission was not effected, but ejaculation took place, and semen was deposited on the vulva. At the time the patient had an open abrasion on the inner surface of one labium majus. A few weeks later, after the abrasion had healed, there appeared in its exact location a small painless erosion. This was followed in a few weeks by general malaise and headache. In May, 1919, she was seen by one of us.

Physical Status.-The patient was obese, but was otherwise in excellent physical condition. Examination of the central nervous system and of the cardiovascular system were negative. On the inner surface of the left labium majus near the fourchet was a small oval erosion about 0.75 by $1.0 \mathrm{~cm}$.,

\footnotetext{
* From the Syphilis Department of the Medical Clinic, Johns Hopkins Hospital.

1. Moore, J. E., and Foley, F. E. B.: Serious Reactions from the Salvarsan and Diarsenol Brands of Arsphenamin: Unusual Blood Pictures with the Report of a Fatal Case, Arch. Dermat. \& Syph. 1:25 (Jan.) 1920. Moore, J. E, and Keidel, A.: Dermatitis and Allied Reactions Following the Arsenical Treatment of Syphilis, to appear in Arch. Int. Med.
} 
slightly elevated, dusky red, indurated and painless. There was slight painless discrete left inguinal adenopathy. Careful examination of the skin, mucous membranes and glands failed to disclose any secondary manifestations. Dark-field examination of the secretion from the labial lesion showed many actively motile Spirochaetae pallidae. The blood Wassermann reaction was positive.

The husband denied any definite history of syphilis but admitted several genital sores early in life. Examination revealed aniscoria, sluggish irregular pupils, and sluggish knee and ankle jerks, more active on the left. The gonads were normal to palpation. The blood Wassermann reaction was positive, but spinal puncture was refused. However, evidence corroborating the clinical diagnosis of neurosyphilis was obtained by the fact that this patient was Wassermann-fast. Twenty-four doses of arsphenamin with interim mercury by inunction failed to reverse the positive blood. Wassermann reaction.

TABLE 1.-Treatment Administered

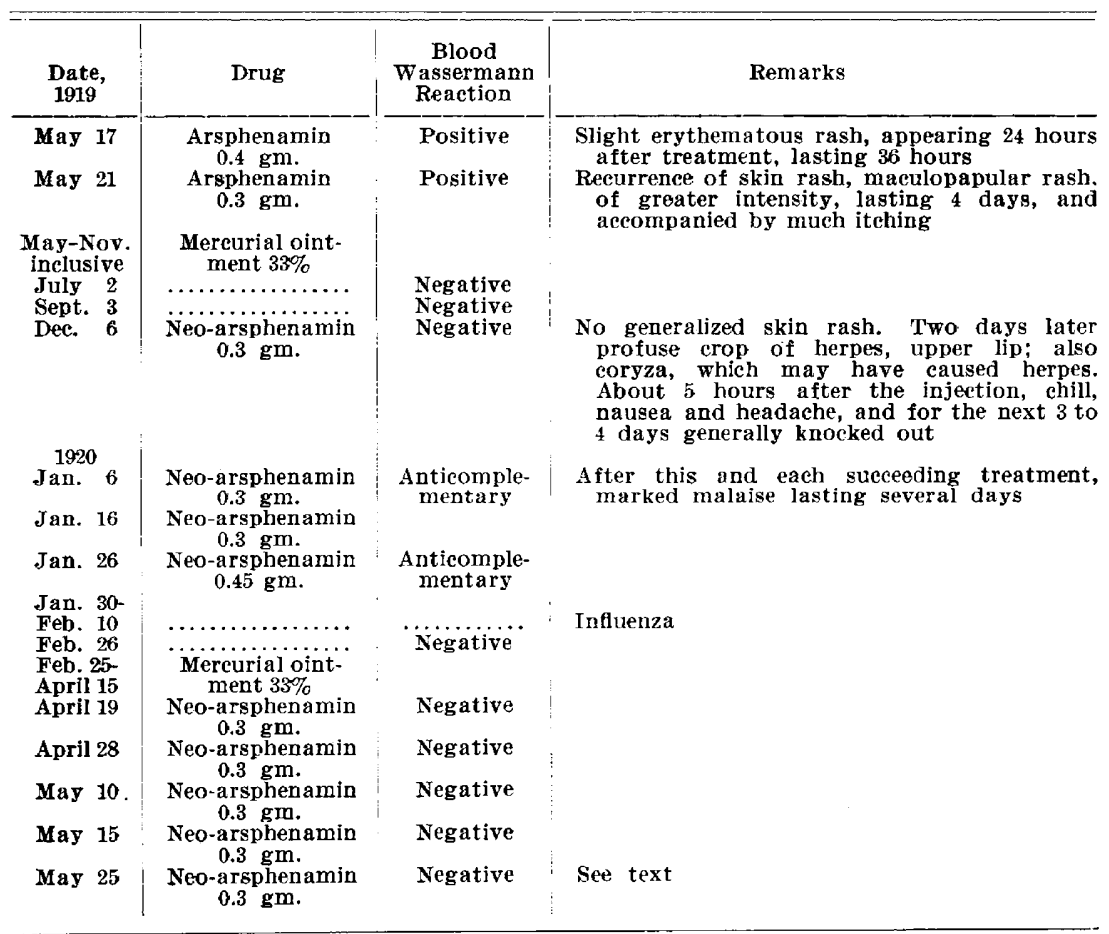

Diagnosis: Primary syphilis, contracted by seminal injection.

Treatment and Course.-Treatment was begun on the day of the first visit and was continued as shown in Table 1 .

After the last treatment, on May 25, the patient left Baltimore for the seashore, where she remained a week. On the train, about six hours after the treatment, she suffered with chilly sensations and vertigo. Within a day or so after her arrival at the shore, she felt miserable and for the next week had some fever, her mouth became sore, and she gradually became jaundiced. On June 2, she returned to Baltimore, and was seen late that evening at her hotel. 
Her temperature was $101 \mathrm{~F}$, pulse 110 . The skin and sclerae were slightly jaundiced. The gums were tender, swollen and bleeding, and the teeth were loose. Around the first upper left molar was a purplish discoloration, and on the hard palate was a huge ecchymosis. Small purpuric spots covered the hands and arms, and there was a large ecchymosis of the left shoulder. During the next two weeks she grew steadily worse and gradually became profoundly ill. Her temperature remained constantly elevated, ranging from 101 to $105 \mathrm{~F}$. Fresh hemorrhages, petechial and ecchymotic, constantly appeared in the skin and mucous membranes, and there was intermittently severe epistaxis, bleeding from the gums and vagina. Blood was found in the urine and stools. The condition of the mouth grew much worse. The gums became purplish red, covered with a thick purulent discharge; the teeth were loose; a large

TABLE 2.-STudies of THE BLoOD

\begin{tabular}{|c|c|c|c|c|c|c|c|c|c|c|c|c|}
\hline \multirow[b]{2}{*}{ 总 } & \multirow{2}{*}{ 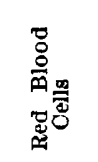 } & \multirow{2}{*}{ 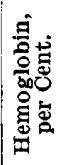 } & \multirow{2}{*}{ 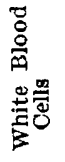 } & \multicolumn{6}{|c|}{ Differential, per Cent. } & \multirow[b]{2}{*}{$\begin{array}{c}\text { Plate- } \\
\text { lets }\end{array}$} & \multirow[b]{2}{*}{ Remarks } & \multirow[b]{2}{*}{$\begin{array}{l}\text { Medica- } \\
\text { tion }\end{array}$} \\
\hline & & & & $\begin{array}{l}\dot{4} \\
\dot{\Sigma} \\
\dot{2}\end{array}$ & $\begin{array}{l}\dot{\theta} \\
\dot{\Sigma} \\
\dot{0}\end{array}$ & $\begin{array}{l}\text { si } \\
\dot{z} \\
\text { م }\end{array}$ & $\begin{array}{l}\dot{2} \\
\dot{2}\end{array}$ & $\begin{array}{l}\dot{\leftrightarrow} \\
\dot{\vec{\Delta}} \\
\dot{H}\end{array}$ & 官 & & & \\
\hline May 25 & $\ldots \ldots \ldots$ & .. & $\cdots$ & $\cdots$ & .. & $\cdots$ & $\cdots$ & $\cdots$ & $\ldots$ & $\ldots \ldots$ & $\cdots$ & $\begin{array}{l}\text { Neo-arsphen- } \\
\text { amin } 0.3 \mathrm{gm} \text {. }\end{array}$ \\
\hline June 4 & $3,176,000$ & 64 & 1,100 & 11.0 & - & 5.0 & 76.0 & 8.0 & - & None & & \\
\hline June 5 & $3,832,000$ & 75 & 1,600 & 17.0 & - & 1.0 & 79.0 & 3.0 & - & $\begin{array}{l}\text { None } \\
\text { seen }\end{array}$ & & \\
\hline June 6 & …..... & .. & $\cdots$ & $\cdots$ & .. & $\cdots$ & $\cdots$ & $\cdots$ & $\cdots$ & $\cdots \cdots$ & . & $\underset{1}{\text { Transfusion }}$ \\
\hline June 7 & $4,128,000$ & 81 & 1,000 & 15.0 & - & - & 78.0 & 7.0 & - & None & & \\
\hline June 9 & $4,192,000$ & 79 & 800 & ... & .. & $\cdots$ & $\cdots$ & $\cdots$ & $\cdots$ & - & $\begin{array}{c}\text { Coagulation } \\
\text { time (Boggg) } \\
6 \text { min. }\end{array}$ & $\underset{2}{\text { Transfusion }}$ \\
\hline 10 & $3,856,000$ & 76 & 600 & 10.6 & - & 1.3 & 81.4 & 5.4 & 1.3 & & & \\
\hline & $4,112,000$ & 74 & 800 & 9.0 & - & $\overline{0}$ & 89.0 & 2.0 & $=$ & 48,000 & & \\
\hline $\begin{array}{ll}16 \\
\text { ee } 14\end{array}$ & $3,4016,000$ & 83. & $\begin{array}{l}950 \\
950\end{array}$ & $\begin{array}{r}12.0 \\
5.0\end{array}$ & $\overline{-}$ & 2.0 & 91.0 & $\begin{array}{l}3.0 \\
2.0\end{array}$ & 二 & & $\begin{array}{c}\text { Coagulation } \\
\text { time } 7 \text { minutes }\end{array}$ & $\underset{3}{\text { Transfusion }}$ \\
\hline June 17 & $4,000,000$ & .. & & $\ldots$ & .. & $\cdots$ & $\ldots$ & $\cdots$ & $\ldots$ & 48,000 & $\begin{array}{l}\text { Vital staining } \\
\text { reticulated cells } \\
0.4 \text { per cent }\end{array}$ & \\
\hline June 18 & $3,872,000$ & 81 & 550 & 4.0 & .. & - & 94.0 & 2.0 & - & 28,000 & Reticulated & \\
\hline June 19 & $3,920,000$ & .. & $\cdots$ & $\cdots$ & .. & $\ldots$ & $\ldots$ & $\cdots$ & $\ldots$ & 36,800 & $\begin{array}{l}\text { Reticulated } \\
\text { oells } 0\end{array}$ & $\underset{4}{T r a n s f u s i o n}$ \\
\hline June 20 & $2,992,000$ & 76 & 900 & 6.0 & - & - & 92.0 & 2.0 & - & & & \\
\hline $\begin{array}{l}\text { June } 21 \\
\text { June } 22\end{array}$ & 3,0 & .. & .. & $\cdots$ & $\because$. & $\cdots$ & $\ldots$ & $\cdots$ & $\cdots$ & $\begin{array}{l}28,800 \\
\cdots \cdots\end{array}$ & Died & \\
\hline
\end{tabular}

necrotic ulcer appeared in the hard palate. Two small pinhead-sized ulcers appeared on the skin, at the angle of the mouth and on one ala nasi, and rapidly increased in size until each was as large as a dime. The base of each was black, composed of necrotic tissue resembling an eschar. Drowsiness was a constant and marked feature, and toward the end the patient complained bitterly of headache. Examination of the heart, lungs and abdomen was always negative.

Treatment was symptomatic only. On June 6, 9, 16 and 19 transfusions of 250 c.c. each of matched citrated blood (Group 4) were administered, without reaction or beneficial effect. The patient gradually grew weaker and died on June 22, four weeks after the onset of the reaction.

Laboratory Data.-Smear from the exudate about the teeth showed many spirochetes and fusiform bacilli, a typical picture of Vincent's angina. 
Urine: Specific gravity was low and fixed (1.002 to 1.010). There was a constant trace of albumin, and after June 10 numerous red blood cells and a strongly positive benzidin test. Phthalein (June 9) was 55 per cent. in two hours.

Stool: June 11, there were no blood (benzidin), ova or parasites. June 18 , there was bloody mucus, benzidin positive. Thereafter blood was constant.

Blood Culture: June 8; the culture was negative. June 19, Friedländer's bacillus (agonal invader?) was found.

Blood Chemistry: June 12, calcium, $9.7 \mathrm{mg}$. per 100 c.c. (normal limits), was found.

Blood: See Table 2.

Necropsy Examination (Dr. Webster).-This was performed ninety minutes after death.

Anatomic Diagnosis: The diagnosis was: extensive subcutaneous and subserous hemorrhages; submucous hemorrhages of stomach, intestines and liver; hemorrhagic nephritis; aplastic bone marrow; lobular pneumonia; edema of lungs; arteriosclerosis.

Body: Numerous large and small petechiae were seen in the skin over the posterior surface of the arms and over the chest and abdomen. The skin of the face and neck was lemon yellow, and over the chest and abdomen, subicteric. The subcutaneous tissues were not edematous. The sclerae and conjunctivae were distinctly yellow. The external nares were occluded by recent hemorrhagic clots and were surrounded by scaly excoriations. There was an ulcer about $1 \mathrm{~cm}$. in diameter on the left side of the nose. Its skin edges were purplish, its base formed by granulation tissue. The entire left side of the nose appeared purplish. A similar ulcer appeared on the mucocutaneous border of the mouth at the right side. The mucous membranes of the mouth were roughened and ulcerated and covered with a purulent material which was also oozing from the region of the gums. On the sides of the neck were a number of small indurated purplish areas.

On opening the peritoneal cavity the serous surfaces appeared smooth and transparent. No free fluid was seen. The small intestines appeared dark, and the transverse colon showed a number of hemorrhages beneath the serosa. The liver and spleen did not extend below the costal margin. On opening the chest cavities no free fluid was seen. The pleural surfaces were delicate and transparent and showed extensive hemorrhages both in the visceral and the parietal layers.

Heart: The heart weighed $325 \mathrm{gm}$. Its epicardial surface was smooth and glistening, showing large and small ecchymoses toward the base. On section the endocardium was also transparent and normal in appearance, although it covered a number of large and small hemorrhages. The cardiac chambers were not dilated or hypertrophied. The valve leaflets were normal. At the base of the aortic and mitral valves a number of atheromatous patches were seen. The coronary arteries also showed signs of arteriosclerosis. The base of the aorta, however, was elastic and lined with a smooth intima.

Aorta: The aorta had lost its elasticity. On section it presented a remarkable picture of advanced and extensive arteriosclerosis. Waxy patches were seen about the orifices of the smaller vessels. Atheromatous ulcers, fresh and hemorrhagic, were' seen throughout its length. One in particular, near the bifurcation, had ruptured through the intima and media, leaving only the thin adventitia.

Lungs: The lungs were deeply pigmented and heavy. Beneath the pleura, particularly of the lower lobes, petechiae and ecchymoses were numerous. On 
palpation several irregular norlules were feit in the lower lobes. On section the lower lobes were found to be congested and showed a few irregularly outlined areas of consolidation about the smaller bronchi. Both lungs were soggy and exuded a large amount of fluid, and the alveoli contained a gelatinous semifluid substance. The bronchi were slightly injected.

Spleen: Its capsule was wrinkled and slightly roughened. On section the cut surface was found to be deep red and firm. The trabeculae and blood vessels and malpighian bodies stood out sharply.

Liver: The liver weighed $1,800 \mathrm{gm}$. and measured 20 by 22 by $10 \mathrm{~cm}$. Its capsule was delicate and transparent. On section the cut surface appeared pale and firm and showed the usual architecture. The lobules stood out distinctly. There was no increase in connective tissue and no areas of necrosis were present. Scattered about were a number of indefinitely outlined hemorrhages.

Suprarenals: The suprarenals weighed $15 \mathrm{gm}$. each and were normal externally and on section.

Kidneys: The kidneys weighed $120 \mathrm{gm}$. each and measured 11 by 6 by $3 \mathrm{~cm}$. The capsule stripped easily, showing a number of small petechiae scattered over the surface. On section the cortex measured about $1.5 \mathrm{~cm}$. in thickness. The striae were parallel and regular. The glomeruli were distinct. Here, also, small hemorrhages were observed. Deep in the pyramids were several large extravasations of fresh blood. The blood in the larger veins had clotted and distencled the lumina. The pelves, however, were smoothly lined and appeared normal. The ureters also showed nothing unusual.

Gastro-Intestinal Tract: The esophagus was normal. The mucous membrane of the stomach showed most extensive hemorrhages, large and small, just beneath the surface. The lumen contained a large amount of hemorrhagic fluid. The remainder of the small intestine was filled with dark clotted fluid which stopped rather abruptly at the ileocecal valve. In the region of the transverse colon and rectum other submucous hemorrhages were seen.

Lymph Glands: The lymph glands were examined carefully and did not appear enlarged. The superficial and deep nodes, however, were red and unusually firm.

Brain: The meninges were normal. There was no thrombosis in the sinuses. Over the convexity just beneath the dura was a small collection of fresh blood which might or might not have been there before death. The convolutions were not flattened. No areas of softening were seen. The blood vessels at the base showed extensive arteriosclerotic changes.

Bone Marrow: The bone marrow from the ribs was red. The cavity of the femur, however, contained only a large amount of fat in which an occasional reddish collection of active marrow was seen.

Microscopic Notes (We are indebted for the following careful description to Dr. W. G. McCallum, who kindly reviewed the available material) :

Bone Marrow: The sections were made from the bone marrow of the femur which was practically entirely composed of fat. There were, in crevices between the fat globules and around the small vessels, sparse accumulations of cells which at first sight seemed to be all of one type. In sections stained successfully with Wright's stain among these cells no megalocaryocytes were found, no nucleated red cells, no eosinophil myelocytes and only rarely a neutrophil myelocyte of normal appearance. Most of the cells were rather smaller than myelocytes and had relatively large rounded, eccentric nuclei which were sharply outlined and filled with large scattered blocks of chromatin, such as are seen in plasma cells. In this respect they differed from normal myelocytes seen in control sections of bone marrow, since in those cells the nucleus was 
more delicately stained, with a clearly defined nucleolus and finely divided chromatin particles. The cytoplasm took a purplish stain, usually without definite evidence of the presence of granules. There was sometimes a pale area about the nucleus. It seemed possible that these cells might be regarded as the basophilic ancestral cells of myelocytes, although they did not correspond with the ordinary descriptions of myeloblasts. A few true myelocytes were discoverable after much search.

It appeared that the bone marrow of the femur at least had ceased entirely to produce the elements of the blood, and any blood formation must be looked for in the bone marrow of the vertebrae and short bones, which was described as red.

Blood formation might also be looked for in the spleen and liver.

Spleen: The spleen was uniform in appearance throughout various sections. The trabeculae, and especially the blood vessel walls, showed rather extensive hyalin changes which became very conspicuous in some sections stained faintly by Wright's stain. The malpighian bodies were rather small but otherwise unchanged. The splenic pulp was fairly full of blood in the sinuses, and there were some extravasations of red corpuscles into the substance. There were numerous minute collections of bacilli in the pulp, surrounded by necrotic cells but by no inflammatory reaction. Between the venules the splenic reticulum contained numerous deeply stained cells exactly resembling those found in the bone marrow. These rather large cells formed conspicuous strands and masses between the venules and were occasionally found within them. Their cytoplasm was basophilic but not distinctly granular, and their nuclei contained abundant large blocks of deeply stained chromatin. They, too, occasionally showed an eccentric pale halo about the nuclets. In most respects they were like plasma cells but they were less regular in form and size and were not obviously and definitely plasma cells.

Liver: The liver showed several large areas of necrosis in each section. These were formed about great masses of bacteria which were chiefly staphylococci, but which were mixed about the edges with abundant bacilli. It will be remembered that in the spleen and kidney only bacilli were found. There was no reaction about the necrotic areas. The tissue in general looked normal so that the bile ducts and portal veins appeared to run in wide bands of connective tissue. This was infiltrated in places with cells which entirely resembled those seen in the splenic pulp. None of these cells were found in the capillaries of the liver lobules.

Kidney: In general the kidney was normal. The epithelium of the tubules was spread apart by dilatation of the convoluted tubules, but it was not markedly degenerated. There were a few scarred areas in which wandering cells were abundant. They had the character of those described in the portal spaces. There were a few small clumps of bacilli with minimal surrounding areas of destruction of the cells.

Lungs: The lungs were extremely edematous, the alveoli being filled with a bloody fluid. Most of the red corpuscles were still visible, but extensive laking seemed to have occurred. There were masses of bacilli scattered everywhere in the alveoli, but there was no pneumonic reaction.

Lymph Glands: The lymph glands were little altered; the lymph cords contained only lymphocytes, and the sinuses were practically empty. There were no large cells like those described. In the mesenteric glands, however, the sinuses contained numerous large phagocytic cells. 


\section{DISCUSSION}

This case provides confirmatory evidence of points developed in our previous communications. ${ }^{1}$ The blood picture is the same as that observed in other cases of stomatitis and of dermatitis exfoliativa. Platelet counts, which were unfortunately lacking in our earlier cases, are provided; they explain the tendency to hemorrhage often noted in cases of this general group. The condition of the bone marrow at necropsy confirms the observation previously made that death may be due to aplastic anemia alone; or, as shown by the absence of inflammatory reaction about the foci of bacteria in the lungs, liver, and spleen, it may result from the destruction of the bodily defense mechanism against bacterial invasion, in which the bone marrow is chiefly concerned.

A careful search of the literature has revealed only three reports of similar cases, aside from those already reported from this clinic.

Labbe and Langlois ${ }^{2}$ report the case of a young woman with secondary syphilis, whose treatment consisted of sixteen injections of neoarsphenamin. The tenth and each succeeding injection were followed by epistaxis and bleeding from the gums, of gradually increasing severity. After the fifteenth injection some purpuric spots appeared on the skin, which increased in severity following the last dose on December 8. Hemorrhages from the nose, gums, and vagina were now severe and the patient died three weeks later. The blood showed the following changes: Red blood cells, 1,601,000; white blood cells, 4,650 (polymorphonuclears 30 per cent., lymphocytes 25 , mononuclears $35)$; coagulation time, nineteen minutes; bleeding time more than one hour. The clot was not retractile. The authors call attention to the blood picture, which they state resembles that of purpura and hemophilia. They believe that the damage was caused by the action of arsenic on the liver.

Eschbach ${ }^{3}$ reports a similar fatal case, following the second dose of neo-arsphenamin. The details are scanty.

Two cases are reported by Görke. ${ }^{4}$ Both patients were women, of whom one died and one recovered. In one instance the drugs employed were sodium arsphenamin and neo-arsphenamin; in the other, silver arsphenamin. The symptoms were the same in both cases, con-

2. Labbé, M., and Langlois, S.: Purpura hémorrhagique aigu par intoxication arsénicale, Bull. et mém. Soc. méd. d. hôp. de Paris 43:786, 1919.

3: Eschbach, H.: Contribution au rôle du novarsénobenzol dans les ictères chez les syphilitiques et dans les dyscrasies sanguines, Bull. et mém. Soc. méd. d. hôp. de Paris 43:1120, 1919.

4. Görke, H.: Auftreten von aplastscher anämie nach Salvarsan, München. med. Wchnschr. 67:1226, 1920. 
sisting of hematemesis, epistaxis, severe skin purpura and necrotic angina. The blood picture was similar to that described in our own case, consisting of anemia, marked leukopenia with an almost complete absence of leukoblastic bone marrow cells and decrease in platelets.

In our opinion, reactions of this type are by no means so rare as the few reports in the literature would indicate. We have shown that damage to the bone marrow, as indicated by changes in the blood picture, is also present in the majority of patients reacting to arsenical drugs, with a rash of the exfoliative dermatitis group, and that these blood changes differ only in degree from the maximally severe reaction, as seen in this case. It has been further demonstrated ${ }^{5}$ that the blood changes may be produced to a mild degree by the administration of an arsenical drug without the occurrence of any reaction. We, therefore, regard as closely interrelated the arsenical reactions of dermatitis exfoliativa, stomatitis, itching and purpura, the connecting link being in the similarity of the alterations in the blood.

In a previous paper ${ }^{1}$ we laid much stress on the recognition of the prodromal symptoms of reactions of the group, and we enumerated as important the occurrence of itching, a mild macular, maculopapular or vesicular rash, prolonged fever, malaise or any tendency toward purpura. Since the preparation of this material, we have had the opportunity of observing several patients in whom such prodromes occurred. In each instance, a study of the blood revealed a slight decrease in neutrophil cells, eosinophilia from 5 to 8 per cent., a slight increase in the large mononuclear transitional group and the presence of numerous fragile leukocytes. The necessity for caution in further treatment was thus strongly emphasized.

While we have nothing to offer regarding the treatment of these reactions, the means we have suggested for their early recognition on the basis of the blood picture represents a definite step toward the prevention of the more severe forms.

SEMMARY

We present the history of a patient who developed a fatal aplastic anemia after neo-arsphenamin. The literature is reviewed, attention is drawn to the relation of this type of reaction to dermatitis exfoliativa following arsphenamin, and the practical application of early recognition of the characteristic blood changes in the prevention of these reactions is pointed out.

5. Moore, J. E.: The Action of Arsenicals on the Blood Picture in Man, Exper. Med., to be published. 